Voix et Images

voixetimages

\title{
Le syndrome Ronfard
}

\section{Bernard Andrès}

Volume 9, numéro 1, automne 1983

Guy Dufresne

URI : https://id.erudit.org/iderudit/200430ar

DOI : https://doi.org/10.7202/200430ar

Aller au sommaire du numéro

\section{Éditeur(s)}

Université du Québec à Montréal

\section{ISSN}

0318-9201 (imprimé)

1705-933X (numérique)

Découvrir la revue

\section{Citer cet article}

Andrès, B. (1983). Le syndrome Ronfard. Voix et Images, 9(1), 163-165.

https://doi.org/10.7202/200430ar d'utilisation que vous pouvez consulter en ligne.

https://apropos.erudit.org/fr/usagers/politique-dutilisation/ 


\title{
Le syndrome Ronfard
}

\author{
par Bernard Andrès, Université du Québec à Montréal
}

Dans un article de juin dernier, Robert Lévesque faisait le bilan de la saison 82-83 : «Le théâtre québécois en panne». ${ }^{1} \mathrm{Je}$ m'en voudrais de revenir sur ce tour d'horizon qui s'imposait alors, au moment où j'écrivais ces lignes, mais dont la pertinence sera moins évidente à la parution de cette présente chronique, l'automne prochain. J'aimerais toutefois revenir sur deux pièces qui clôturaient la saison dernière et dont l'une reviendra en janvier sur les planches du TNM : la Passion de Juliette, de Michelle Allen. ${ }^{2}$ Pièce charnière entre deux saisons; pièce de transition également, entre deux moments de la jeune dramaturgie québécoise. Sans prétendre évaluer une orientation d'ensemble, il est possible de déceler, au creux de cette vague ou de cette panne théâtrale, une nouvelle inspiration que $\mathrm{j}$ 'appellerais volontiers le «syndrome Ronfard». Exception faite des scénographies de Brassard qui investit Ottawa, que se passe-t-il vraiment d'intéressant sur nos scènes depuis deux ans (depuis les États généraux du Théâtre québécois de novembre 1981)? Période de latence où les troupes expérimentales se scindent ou se resituent (Nouveau Théâtre expérimental, Théâtre expérimental des Femmes, Eskabel, notamment). Transition pour les grandes compagnies où les «pères» se retirent l'un après l'autre (Pelletier à la NCT, Roux au TNM, Germain au Théâtre d'Aujourd'hui). Constitution d'une forme de tradition théâtrale parmi les femmes dont les spectacles et festivals de plus en plus nombreux commencent à fonder autour du féminisme une doxa bien établie. Si chaque nouveau spectacle vient la conforter ou la subvertir, aucun d'entre eux ne peut feindre à présent de l'ignorer. Notons à ce propos que la tâche de la critique s'en trouve facilitée dans la mesure où, les points de référence ne manquant pas, nulle

1. «Le théâtre québécois en panne», in le Devoir, 11 juin 1983.

2. La Passion de Juliette, de Michelle Allen. Productions Germaine Larose. Mise en scène de l'auteure. Costumes de Jacynthe Vézina, Pauline St-Laurent et Lucille Benoît. Musique de Catherine Gadouas, chorégraphies de Dulcinée Langfelder. Á la salle André Pagé de l'École nationale de Théâtre. Juin 1983. 
complaisance n'est plus possible pour les pièces qui négligent le chemin parcouru et par la redite, commencent à installer clichés et stéréotypes dans l'avant-garde au féminin. N'est-ce pas ce qui guettait Vol. P-459 de Danielle Fournier, présentée dans le cadre de la "Quarantaine» du thêâtre expérimental de l'Eskabel, en mai dernier? ${ }^{3}$ Cette pièce mettait en scène deux personnages féminins autour de quelques chansons de cabaret et d'un rapaillage de textes épars sur l'autobiographie féminine, la femme dans la chanson populaire, la représentation photographique et les rapports hétérosexuels. Autant d'observations déjà bien menées dans maints spectacles du genre et qui là, n'arrivaient pas à convaincre l'auditoire (reprise trop convenue de la doxa évoquée plus haut?). L'impression de repartir à zéro dans un montage peu contrôlé où ne prime que le plaisir de jouer, fondé sur l'établissement d'une communication facile avec l'auditoire féminin. Seuls le jeu sur les traductions textuelles et la qualité des arrangements musicaux de Flora Chiasson, conféraient une certaine tenue au spectacle.

Mon propos n'est pas de comparer celui-ci à la Passion de Juliette mais de situer la pièce de Michelle Allen dans un nouveau courant (non exclusivement) féministe, susceptible de nous sortir de l'impasse. On pourrait aisément repérer dans la Passion quelque procédé d'écriture mis à l'œuvre par Ronfard et son équipe au NTE et surtout dans le fameux Roi boiteux (je ne parle pas de la Mandragore qui n'en est qu'un modèle réduit «à l'usage TNM») :

- insertion d'une intrigue prosaïque, voire triviale, dans un ensemble plus vaste, alimenté par les grands problèmes d'actualité;

- hybridisation du langage populaire et des références culturelles savantes;

- téléscopage de l'espace, du temps, du réel et de l'imaginaire et surtout:

- humour, goût prononcé pour l'aspect spectaculaire du jeu théâtral;

- contact avec le public, occupation débordante de l'aire et du volume scéniques;

- recherche dans les décors et costumes d'une "grossièreté apprêtée», d'un «savant effet fruste» (étoffes, cuirs savamment vieillis, etc.).

Autant de symptômes trahissant à coup sûr le «syndrome Ronfard». On ne saurait reprocher à Michelle Allen d'en avoir été affectée. Comme il l'avait fait de façon débridée avec les classiques occidentaux (surtout Shakespeare), elle entreprend pour sa part de réécrire Roméo et Juliette (du point de vue de Juliette, naturellement). Du chef-d'œuvre ressassé par la

3. Vol. P-459, de Danielle Fournier. Mise en scène d'Alain Gabriel. Avec Martine Michaud, Michèle Boulet et Flora Chiasson. Présentation de l'Eskabel au Centre Calixa-Lavallée, mai 1983. 
tradition et les traductions, il ne reste que peu de chose, chez Allen. Sinon la passion, précisément. L'outrance de ses manifestations dans l'amour, bien sûr, mais aussi bien dans l'amour-propre : l'apprentie-sorcière qui expérimentait in vitro sur «la molécule amour» finira par éprouver elle-même les effets troublants de «la chute libre»... à son corps défendant. Michelle Allen réussit là où, en début de saison, le Roméo et Julien de Robinson et Girard n'avait produit qu'une simple pochade. ${ }^{4} \mathrm{La}$ Passion de Juliette, c'est Shakespeare détrôné par Lewis Caroll, en régime carnavalesque et sur fond disco. Ducharme est de la partie, aussi discrètement que la Belle et la Bête de Cocteau, au hasard d'une réplique, d'un jeu de scène ou d'un parti-pris costumier (les bottes en caoutchouc d'Inespérée, l'amour impossible d'Inattendu), Joyeux travestissement du patrimoine culturel aussi bien québécois qu'international, au gré d'une recherche «science-fictionneuse» sur l'amour en chute libre chez les pigeons voyageurs. Jamais ou presque le rythme ne faiblit dans cette époustouflante occupation des lieux. Reste à savoir comment s'effectuera le passage de la petite salle expérimentale André Pagé, à la scène à l'italienne du TNM. Michelle Allen n'y assumera plus la mise en scène. Aura-t-elle d'ici là coupé dans la première partie qui accuse quelques longueurs par rapport aux scènes-clés du carnaval, du retour du fils perdu, de la séduction et du duel amoureux? Souhaitons toujours que des pièces de cette nature égayent nos scènes à venir, en redonnant aux institutions qui boudent la création québécoise, le goût de reprendre des risques, l'an prochain.

4. Cf. la chronique de cette pièce dans Voix et Images, vol. VIII, no 3, pp. 523-524. 